\title{
SISTEM INFORMASI PENDATAAN PENGAMBILAN BPKB MOTOR PADA FEDERAL INTERNASIONAL FINANCE SAMARINDA
}

\author{
Irwan Ukkas ${ }^{1)}$, Tabrani Rija' '2), Erich Andicha ${ }^{3)}$ \\ ${ }^{1,2}$ Sistem Informasi, Stmik Widya Cipta Dharma \\ ${ }^{3}$ Sistem Informasi, Stmik Widya Cipta Dharma \\ $1,2,3$ Jl. Prof. M. Yamin No. 25, Samarinda, 75123 \\ E-mail : Irwan212@yahoo.com ${ }^{1)}$,Tabrani_69@yahoo.com ${ }^{2}$, informatikawicida@gmail.com ${ }^{3)}$
}

\begin{abstract}
ABSTRAK
Sistem Informasi Pendataan Pengambilan BPKB Motor merupakan sistem yang dibangun untuk proses pengolahan Data pengambilan BPKB Motor berupa input data konsumen, data merk motor, transaksi pengambilan BPKB Motor serta pelaporannya.

Penelitian ini dilakukan pada Federal International Finance Samarinda yang beralokasi di Samarinda dengan menggunakan metode penelitian yaitu metode pengumpulan data, studi lapangan, studi pustaka, analisis kebutuhan, desain sistem, dan implementasi sistem. Program yang telah dibangun berjudul Sistem Informasi Pendataan Pengambilan BPKB Motor dengan desain sistem mengunakan Flow Of Document (FOD), Data Flow Diagram (DFD) dan Hirachy Plus Input Process Output (HIPO).

Aplikasi Ini dibangun menggunakan software yaitu Bahasa Pemrograman Visual Basic 6.0, database yang digunakan Microsoft Access 2007. Sistem yang dibangun beroperasi pada Sistem Operasi WindowsDari hasil implementasi sistem, dapat disimpulkan bahwa dengan penggunaan software dapat membantu bagian rekam medis dalam mengelola rekam medis pasien pada Rumah Sakit Atma Husada Mahakam Samarinda. Serta penulis memberikan saran bahwa sistem yang berjalan ini masih sederhana dan masih dapat dikembangkan sebagai acuan untuk lebih baik lagi.

Dari hasil implementasi sistem, dapat disimpulkan bahwa dengan penggunaan software dapat membantu dalam proses Pengambilan BPKB Motor Pada Federal International Finance Samarinda. Serta penulis memberikan saran agar Federal International Finance Samarinda membuat koneksi jaringan komputer ke masing-masing bagian untuk memudahkan pengolahan data.
\end{abstract}

Kata Kunci : Sistem Informasi, Pendataan Pengambilan BPKB

\section{PENDAHULUAN}

Informasi Pendataan Pengambilan Buku Pemilik Kendaraan Bermotor (BPKB) merupakan program yang digunakan dalam proses pengolahan pengambilan BPKB Motor meliputi input data konsumen yang sudah lunas, input data BPKB serta sampai pada pelaporannya yang meliputi daftar konsumen, daftar pengambilan BPKB Motor.

Pada Federal International Finance Samarinda, dalam pengolahan data pengambilan BPKB Motor masih menggunakan bantuan Ms. Word dan Ms. Excel, dimana proses pencarian konsumen yang sudah lunas motornya memerlukan waktu yang lama.

Dalam mengolah data pengambilan BPKB Motor pada Federal International Finance Samarinda, sampai saat ini belum didukung oleh tersedianya suatu sistem berbasis komputer yang dapat memudahkan dalam pengolahan data sehingga menyebabkan ketidakpraktisan dalam pengelolaan data, keterlambatan penyediaan informasi mengenai pengambilan BPKB Motor.

Menyadari permasalahan di atas, peneliti memandang perlu untuk menemukan solusi bagi terwujudnya pengelolaan data pengambilan BPKB
Motor secara mudah dan penyediaan informasi secara cepat, tepat dan akurat serta menghindari masalah akibat kesalahan manusia dengan membuat suatu Sistem Informasi Pendataan Pengambilan BPKB Motor Pada Federal International Finance Samarinda.

\section{RUANG LINGKUP PENELITIAN}

Dalam penelitian ini permasalahan mencakup

1. Cakupan Masalah

Permasalahan yang terjadi pada Rumah Sakit Atma Husada Mahakam adalah Dalam mengolah data pengambilan BPKB Motor pada Federal International Finance Samarinda, sampai saat ini belum didukung oleh tersedianya suatu sistem berbasis komputer yang dapat memudahkan dalam pengolahan data sehingga menyebabkan ketidakpraktisan dalam pengelolaan data, keterlambatan penyediaan informasi mengenai pengambilan BPKB Motor.

2. Batasan-batasan penelitian Input Data :

1. Input Data Konsumen

2. Input Data Merk Motor 
Transaksi

\section{Pengambilan BPKB}

\section{Output}

1. Daftar Konsumen

2. Daftar Merk Motor

3. Daftar Pengambilan BPKB Motor

4. Grafik Pengambilan BPKB Motor Berdasarkan Merk, Type Motor dan Pertahun.

3. Rencana hasil yang didapatkan

Menghasilkan suatu Sistem Informasi Pendataan Pengambilan BPKB Motor Pada Federal International Finance Samarinda, yang selama ini menggunakan sistem manual beralih dengan menggunakan sistem komputerisasi sehingga dapat bermanfaat dalam pelaksanaan kegiatan pembuatan laporan pengambilan BPKB Motor Pada Federal International Finance Samarinda

\section{BAHAN DAN METODE}

\subsection{Penjelasan Bahan}

Sistem adalah jaringan dari prosedur-prosedur yang saling berhubungan, berkumpul bersama-sama untuk melakukan suatu kegiatan atau untuk menyelesaikan suatu sasaran yang tertentu. (Jogiyanto, 2003)

Informasi adalah kumpulan data yang diolah menjadi bentuk yang lebih berguna dan lebih berarti yang menerimanya (Kristiato, 2003).

Sistem Informasi adalah seperangkat komponen yang saling berhubungan yang berfungsi mengumpulkan, memproses, menyimpan dan mendistribusikan informasi untuk mendukung pembuatan keputusan dan pengawasan dalam organisasi (Fakhri, 2005)

data adalah fakta yang tidak sedang digunakan pada proses keputusan, biasanya dicatat dan diarsipkan tanpa maksud untuk segera diambil kembali untuk pengambilan keputusan (Murdick dalam Kumorotomo dan Margono, 2002).

Pengolahan data adalah manipulasi data atau transformasi simbol-simbol seperti angka dan abjad untuk tujuan menigkatkan kegunaanya. Pengolahan data tidak hanya melibatkan perhitungan numeris, tetapi juga operasi-operasi klasifikasi seperti klasifikasi data dan perpidahan data dari suatu tempat ketempat lain, pengurutan data, penggabungan data dan lain-lain (Teguh, 2003).

Visual Basic adalah bahasa yang sebenarnya cukup mudah untuk dipelajari. Bagi programmer pemula yang baru ingin belajar program, lingkungan Visual Basic dapat membantu membuat program berbasisi Windows dengan sekejap mata. Sedang bagi programmer tingkat lanjut, kemampuannya yang besar dapat digunakan untuk membuat program- program yang kompleks, misalnya seperti dalam lingkungan networking atau client-server

Database adalah kumpulan fakta-fakta sebagai representasi dari dunia nyata yang saling berhubungan dan mempunyai arti tertentu, database digunakan untuk menyimpan data agar data tersebut dapat dimanipulasi dengan mudah, terjamin keakuratannya, efesien dalam penyimpanan, dan tentu saja dapat dengan mudah untuk diakses kembali. (Robin, 2005)

\subsection{METODE}

Metode yang digunakan dalam menganalisis data ini adalah menggunakan metode waterfall. Pada metode ini terdapat 5 (lima) tahap untuk mengembangkan suatu perangkat lunak. Kelima tahapan itu tersusun dari atas kebawah, diantaranya Analisis, Design, Coding, Testing, dan Maintenance. Konsep dari metode ini adalah melihat bagaimana suatu masalah secara sistematis dan terstruktur dari atas kebawah. Tahap-tahap pengembangan perangkat lunak metode waterfall dapat dilihat pada gambar 3.1

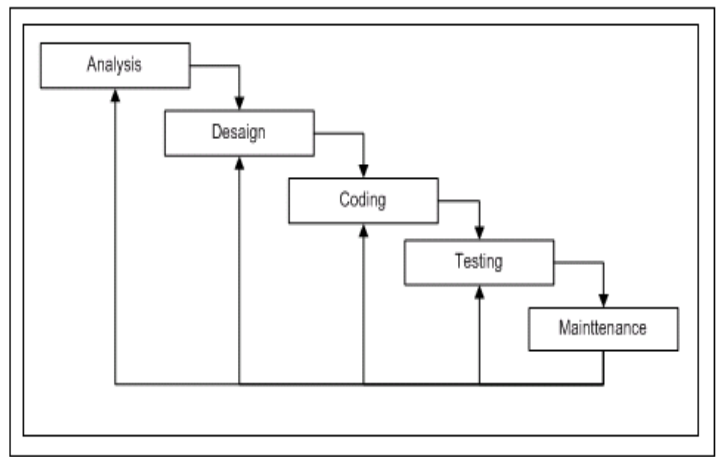

Gambar 1. Model Pengembangan Air Terjun

\section{RANCANGAN SISTEM/APLIKASI}

1. Flow Of Document (FOD) Yang Berjalan

Dari Flow Of Document yang sedang berjalan bahwa Sistem Informasi Pendataan Pengambilan BPKB Motor Pada Federal International Finance Samarinda dimulai pada entitas konsumen yang memberikan dokumen data konsumen yang dialirkan ke entitas administrasi. Pada entitas administrasi dokumen tersebut di isi secara manual sehingga menghasilkan dokumen daftar konsumen. Pada entitas administrasi juga terdapat dokumen data merk motor yang di proses secara manual dan menghasilkan dokumen daftar merk motor. Proses pengambilan bpkb motor dilakukan pada entitas administrasi yang mendapat aliran data dari dokumen data konsumen dan dokumen data merk motor, prosesnya secara manual dan menghasilkan dokumen daftar pengambilan bpkb. Proses pembutan laporan dilakukan secara manual yang mendapat aliran data dari dokumen data konsumen, merk motor dan 
pengambilan bpkb yang mengahsilkan daftar konsumen, daftar merk motor dan laporan pengambilan bpkb motor yang diserahkan ke entiatas Pimpinan. Proses selesai pada entitas Pimpinan.

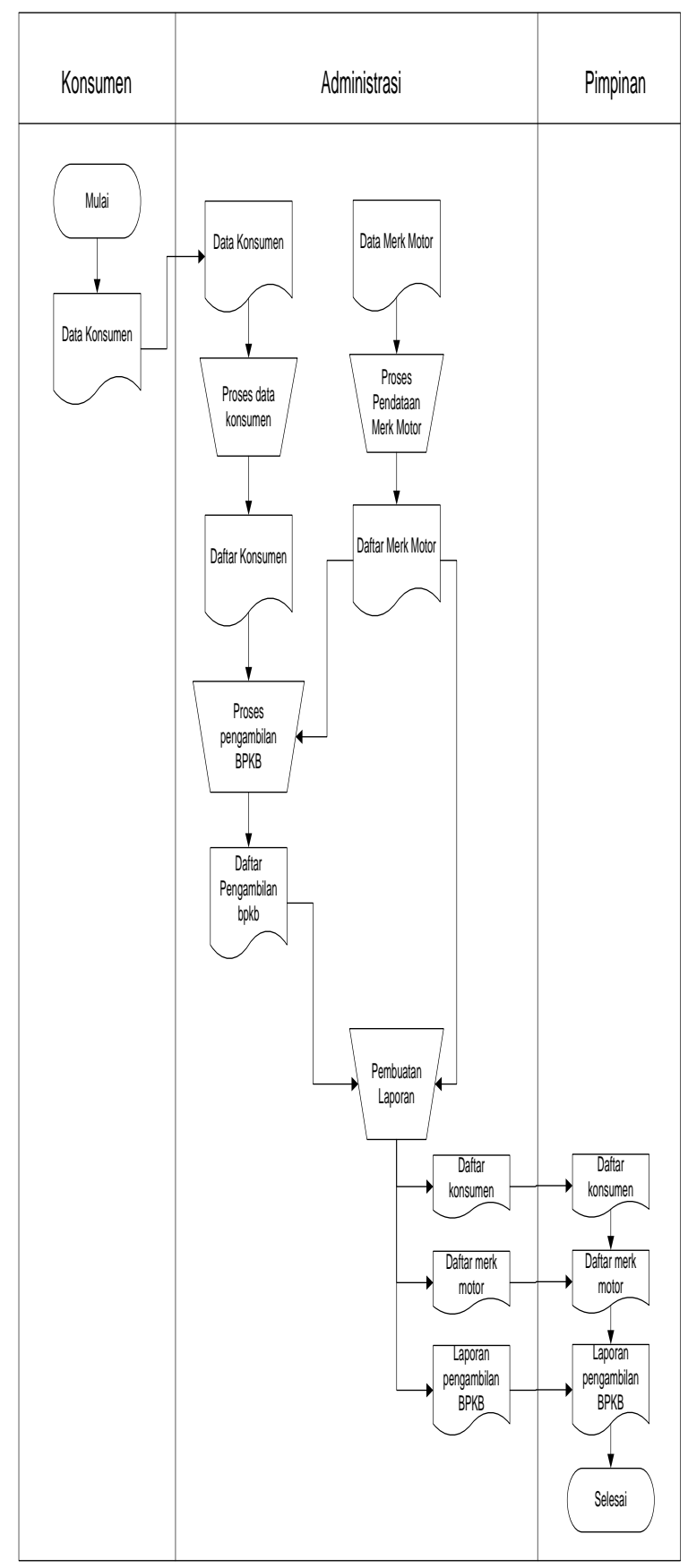

Gambar 2. FOD Yang Berjalan

2.

low Of Document (FOD) Yang Diusulkan

Dari Flow Of Document yang sedang diusulkan bahwa Sistem Informasi Pendataan Pengambilan BPKB Motor Pada Federal International Finance Samarinda dimulai pada entitas konsumen yang memberikan dokumen data konsumen yang dialirkan ke entitas administrasi. Pada entitas administrasi dokumen tersebut diinput lewat keyboard lalu diproses secara komputerisasi dan disimpan dalam data base konsumen sehingga menghasilkan dokumen daftar konsumen. Pada entitas administrasi juga terdapat dokumen data merk motor yang diinput lewat keyboard lalu diproses secara komputerisasi dan disimpan dalam database merk motor sehingga menghasilkan dokumen daftar merk motor. Proses pengambilan bpkb motor dilakukan pada entitas administrasi yang mendapat aliran data dari database konsumen dan database merk motor, prosesnya dilakukan secara komputerisasi yang kemudian disimpan dalam database pengambilan bpkb dan menghasilkan dokumen daftar pengambilan bpkb. Proses pembutan laporan dilakukan secara komputerisasi yang mendapat aliran data dari database konsumen, merk motor dan pengambilan bpkb sehinggan menghasilkan daftar konsumen, daftar merk motor, laporan pengambilan bpkb motor dan grafik pengambilan bpkb motor lalu diserahkan ke entiatas Pimpinan. Proses selesai pada entitas Pimpinan.

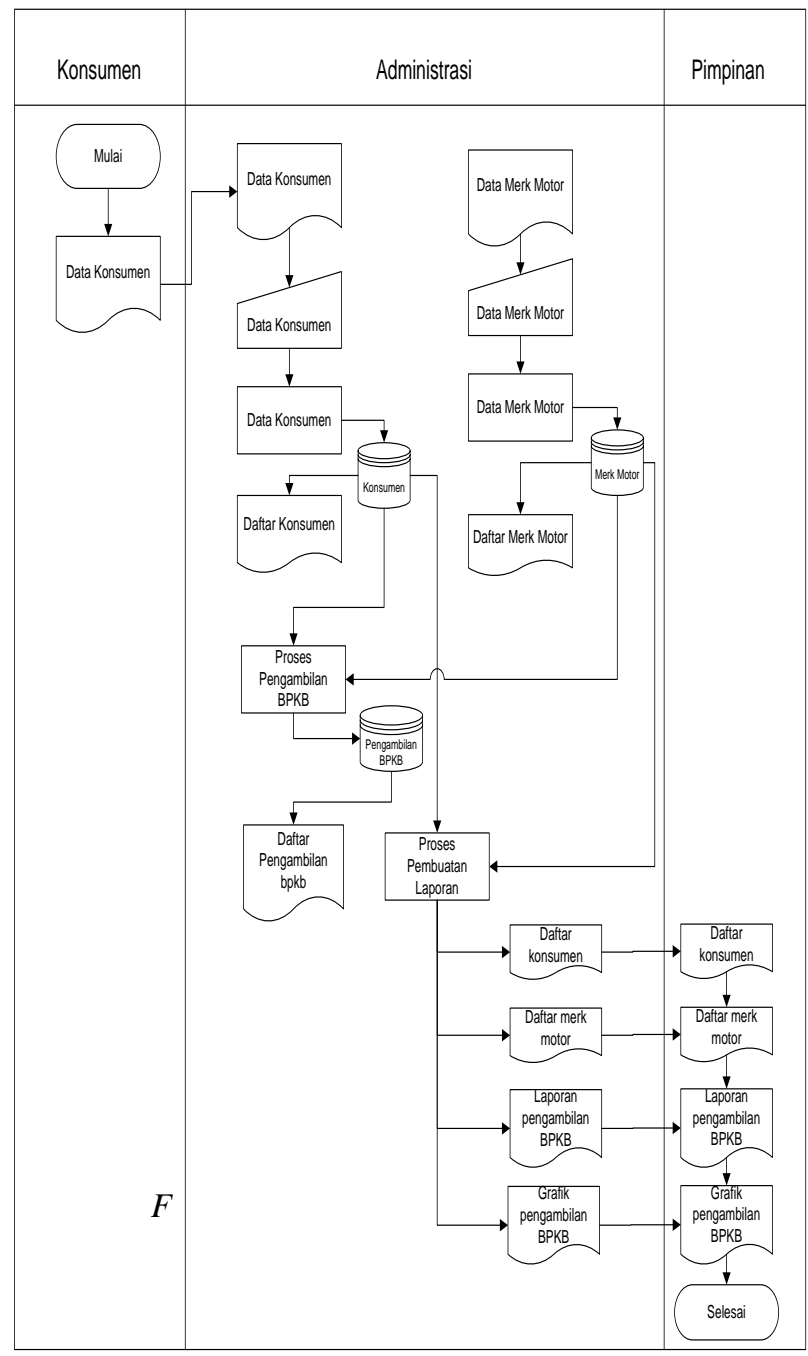

3.

\section{Gambar 3. FOD Yang Diusulkan}

ontext Diagram

Pada gambar diatas terdapat 3 (Tiga) entitas, yaitu entitas konsumen memberikan data konsumen ke sistem. Entitas 
Administrasi memberikan data merk motor dan data pengambilan bpkb ke sistem. Dan Entitas Pimpinan mendapatkan tiga laporan berupa daftar konsumen, daftar merk motor, laporan pengambilan bpkb motor dan grafik pengambilan bpkb motor dari system.

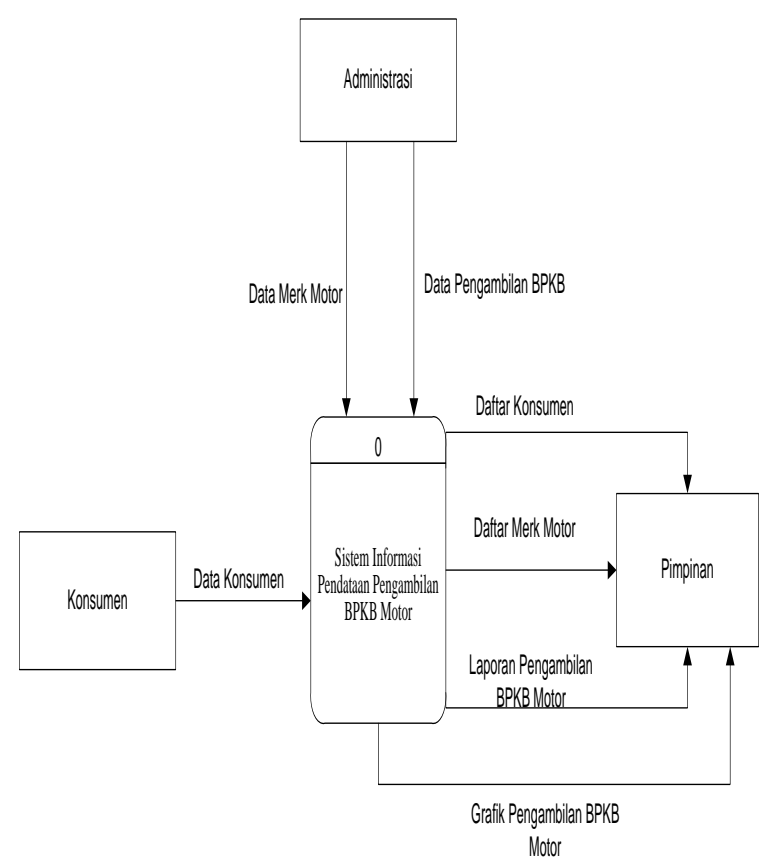

Gambar 4. Context Diagram

4.

ata Flow Diagram (DFD) Level 0

DFD Level 0 diatas Entitas konsumen menjadi sumber data konsumen yang dikemudian dilakukan proses pendataan konsumen yang datanya disimpan dalam penyimpanan data (data store) data konsumen. Entitas administrasi menjadi sumber data merk motor dan data pengambikan bpkb yang datanya disimpan dalam penyimpanan data (data store) merk motor dan pengambilan bpkb. Proses pengambilan bpkb motor mendapat aliran dari database kondumen dan merk motor. Proses pembuatan laporan memperoleh data dari data store konsumen, merk motor dan pengambikan bpkb dimana menghasilkan daftar konsumen, daftar merk motor, laporan pengambilan bpkb motor dan grafik pengambilan bpkb motor yang kemudian di alirkan ke entitas pimpinan.

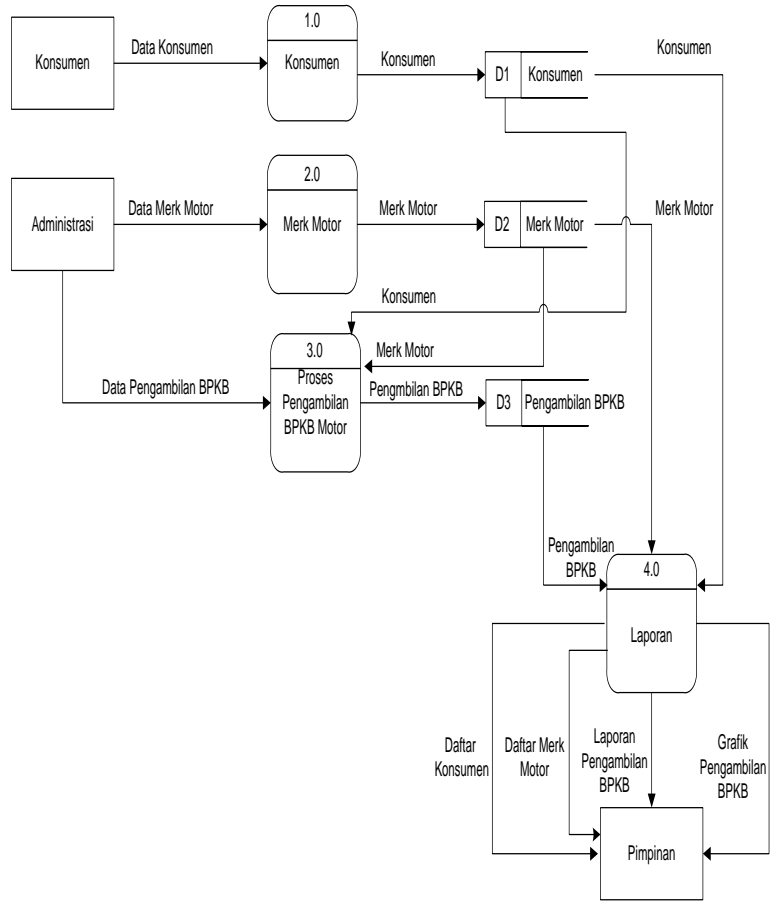

Gambar 5. Data Flow Diagram (DFD) Level 0

5.

ata Flow Diagram (DFD) Level 1

DFD level 1 diatas dimulai dari data store konsumen yang menghasilkan laporan daftar konsu円pen yang kemudian dialirkan ke entitas pimpinan. Data store merk motor yang menghasilkan laporan daftar merk motor yang kemudian dialirkan ke entitas pimpinan. Data store pengambilan bpkb yang menghasilkan laporan pengambilan bpkb motor dan grafik pengambilan bpkb motor yang kemudian dialirkan ke entitas pimpinan.

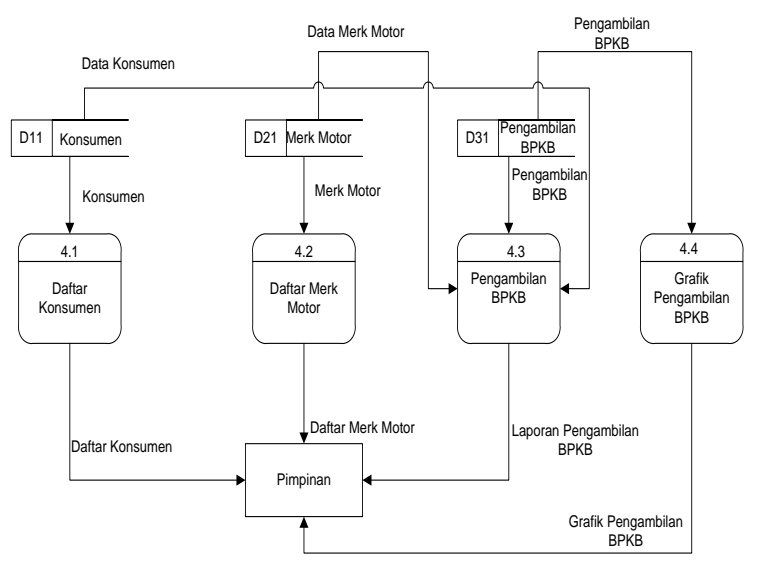

Gambar 6. Data Flow Diagram (DFD) Level 1

6. HIPO (Hirarchy Plus Input-Proses-Output)

HIPO Sistem Informasi Pendataan Pengambilan BPKB Motor terdapat proses 
input data konsumen, proses input data merk motor, proses input pengambilan $\mathrm{BPKB}$, dan proses laporan. Untuk proses laporan terdapat empat proses yaitu proses daftar konsumen, proses daftar merk motor dan proses laporan pengambilan BPKB dan laporan grafik pengambilan $\mathrm{BPKB}$.

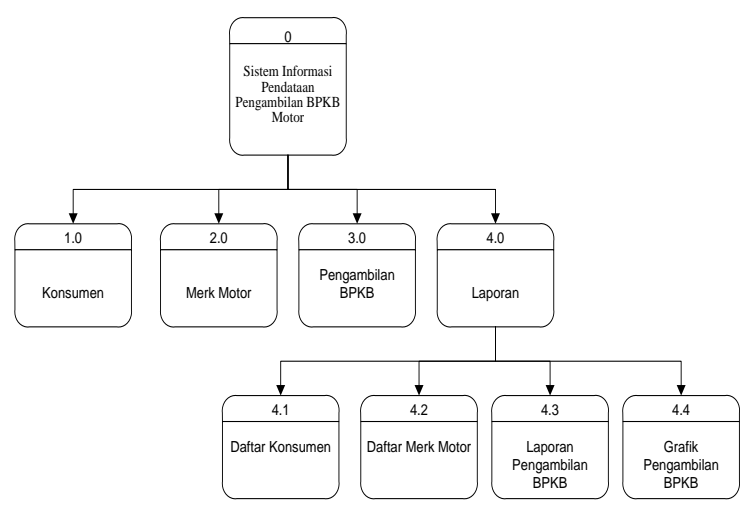

\section{Gambar 7. Data Flow Diagram (DFD) Level 1}

4

\section{MPLEMENTASI}

1.

nput Data Konsumen

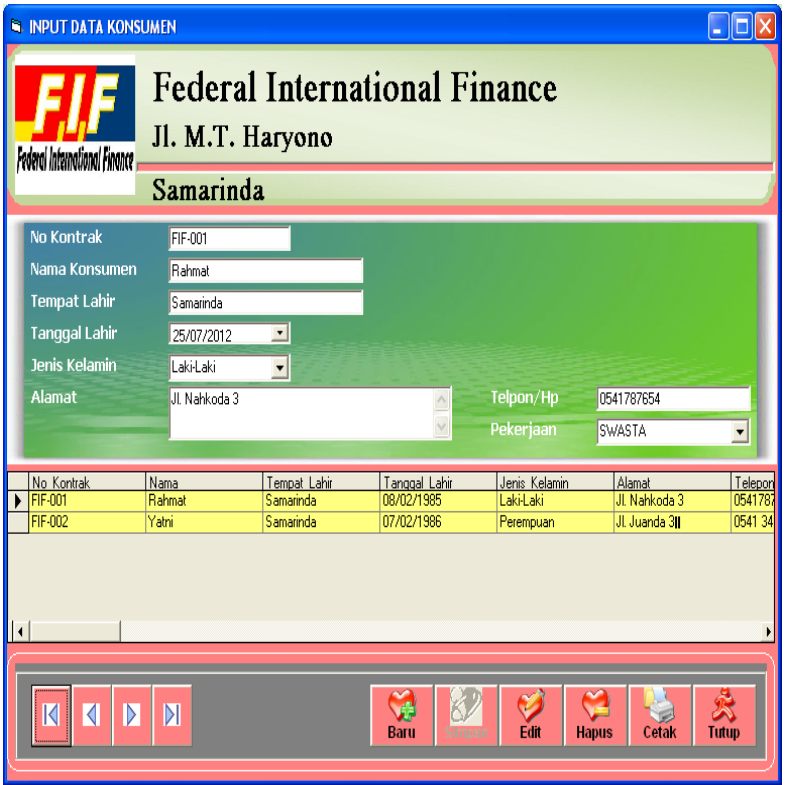

Gambar 7. TampilanForm Input Data Konsumen

Seperti yang terlihat pada gambar 7, form input data konsumen untuk menginputkan data konsumen berupa no kontrak, nama konsumen, tempat lahir, tanggal lahir, jenis kelamin, alamat, telpon/hp dan pekerjaan.

\section{Input Data Data Merk Motor}

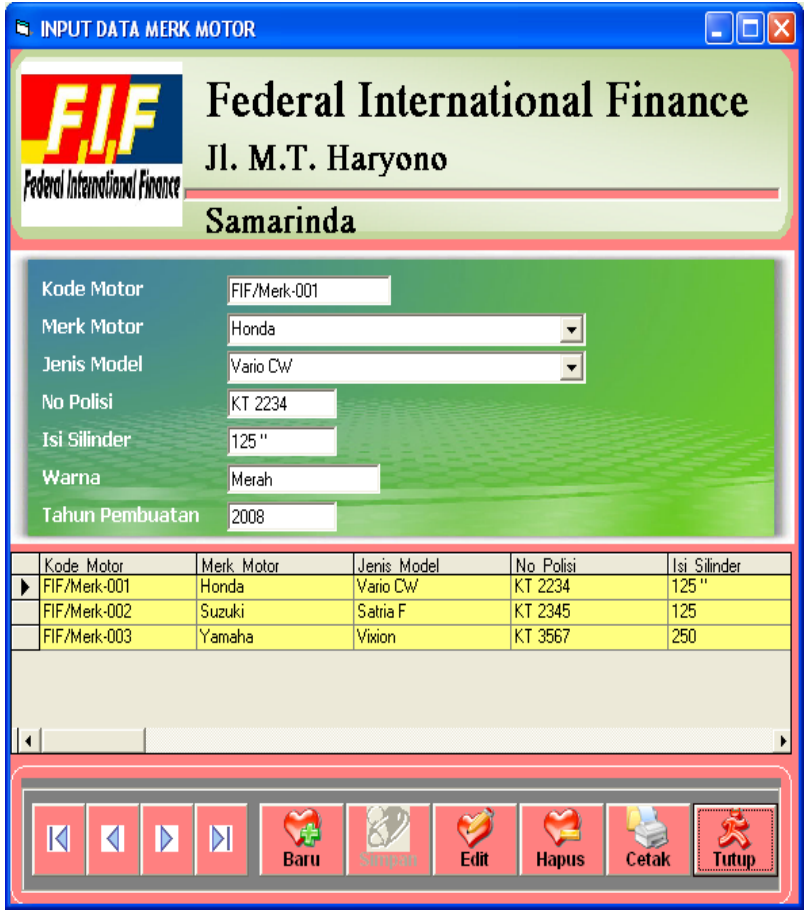

Gambar 8. Tampilan Form Input Data Merk Motor

I Seperti yang terlihat pada gambar 8, form input data Merk Motor digunakan untuk menginputkan data berisikan kode motor, merk motor, jenis model, isi silinder, warna dan tahun pembuatan

\section{Tampilan Transaksi Pengambilan BPKB}

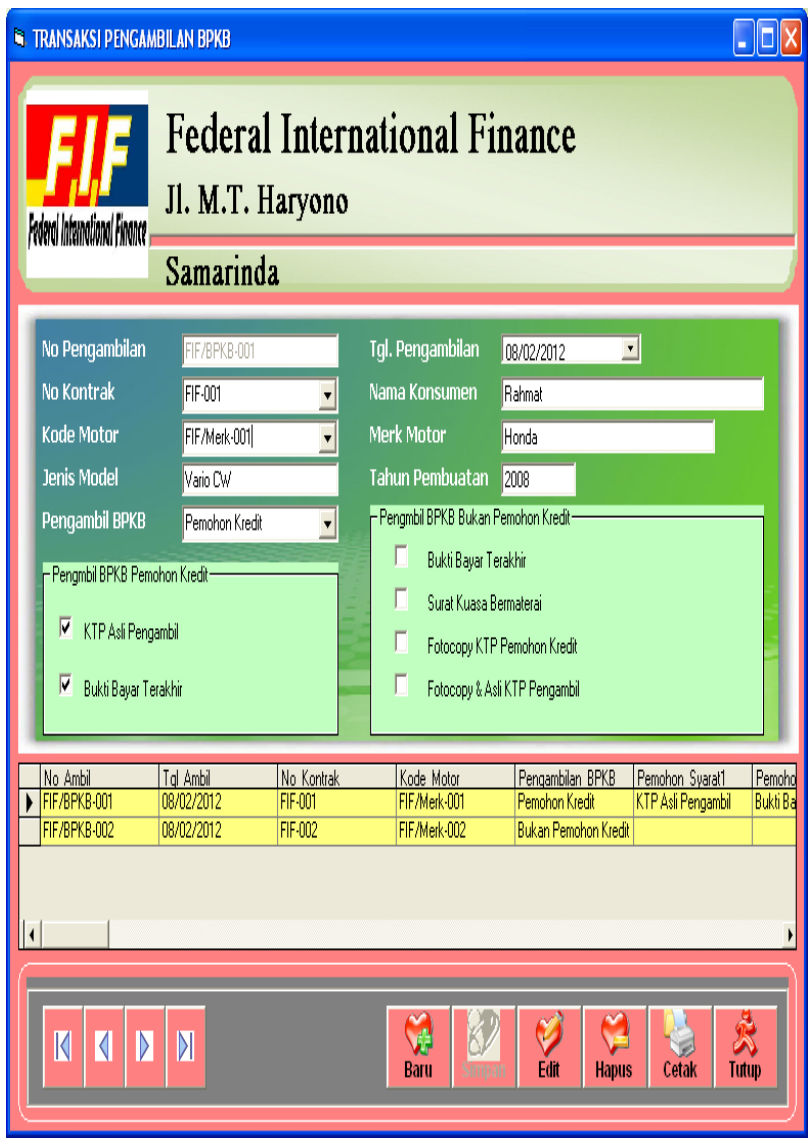




\section{Gambar 9. Tampilan Transaksi Pengambilan BPKB}

Seperti yang terlihat pada gambar 9. form input data obat digunakan untuk menginputkan inputan datanya berisikan no pengambilan, no kontrak, nama konsumen, tgl pengambilan, kode motor, merk motor, jenis motor, tahun pembuatan, pengambil bpkb, pengambil syarat1, pengambil syarat2, bukan pengambil syarat1, bukan pengambil syarat2, bukan pengambil syarat3 dan bukan pengambil syarat 4 .

4. Tampilan Grafik Pengambilan BPKB Perbulan

\section{GRAFIK PENGAIBILAN BPKB PERBULAN BERDASARKAN MERK MOTOR}

Buln : PEBRUARI 2012

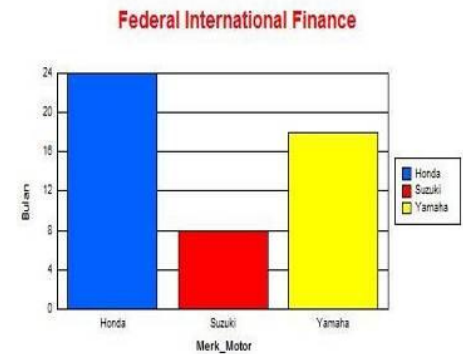

\section{Gambar 10Tampilan Grafik Pengambilan BPKB Perbulan Berdasarkan Merk Motor}

Seperti yang terlihat pada gambar 10. Tampilan Grafik Pengambilan BPKB Perbulan merupakan tampilan grafik pengambilan BPKB perbulan berdasarkan merk motor. Informasi ini diperoleh dari input transaksi pengambilan BPKB.

\section{Tampilan Grafik Pengambilan BPKB Pertahun}

\section{GRAFIK PENGAMBILAN BPKB PERTAHUN}

Bulan : 2012

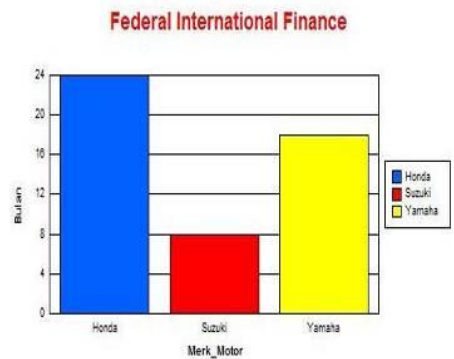

\section{Gambar 11 Tampilan Grafik Pengambilan BPKB Pertahun}

Seperti yang terlihat pada gambar 11. Tampilan grafik pengambilan BPKB pertahun merupakan tampilan grafik pengambilan BPKB pertahun. Informasi ini diperoleh

6. Tampilan Grafik Pengambilan BPKB Perbulan Berdasarkan Type Motor

\section{GRAFIK PENGAMBILAN BPKB PERBULAN BERDASARKAN TYPE MOTOR}
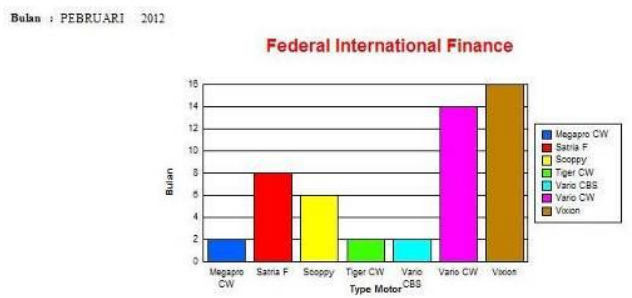

\section{Gambar. 12. Tampilan Grafik Pengambilan BPKB Perbulan Berdasarkan Type Motor}

Seperti yang terlihat pada gambar 12. Tampilan grafik pengambilan BPKB perbulan berdasarkan type motor merupakan tampilan grafik pengambilan BPKB perbulan berdasarkan type motor. Informasi ini diperoleh dari input transaksi pengambilan BPKB

\section{KESIMPULAN}

Setelah penulis mengadakan penelitian pada Federal International Finance Samarinda, maka penulis dapat menyimpulkan sebagai berikut :

1. Dengan adanya Sistem Informasi Pendataan Pengambilan BPKB Motor Pada Federal International Finance Samarinda dengan menggunakan pemrograman visual basic 6.0 dapat memberikan solusi dalam pengolahan data BPKB dan pelaporannya.

2. Sistem yang telah dibangun dapat menampikan laporan daftar konsumen, daftar merk motor, laporan pengambilan BPKB secara keseluruhan maupun bulanan sampai menghasilkan grafik pengambilan BPKB motor perbulan berdasarkan merk motor.

3. Sistem yang telah dibangun terdapat login yang otorisasinya telah diatur yaitu admin dan user dimana hak akses dari user tersebut berbeda.

\section{SARAN}

Adapun saran yang penulis berikan kepada Federal International Finance Samarinda untuk perbaikan sistem adalah:

1. Agar karyawan pada bagian administrasi diberikan pengetahuan bagaimana mengoperasikan sistem informasi dan dapat menangani sendiri jika terjadi kerusakan pada sistem komputer.

2. Agar kedepannya sistem ini dapat di buat di area Jaringan dan Website dan sehingga dapat di operasikan lebih dari 1 unit komputer sehingga pelayanan kepada konsumen lebih maksimal. 


\section{DAFTAR PUSTAKA}

Agus, 2003, Sistem Informasi Manajemen terjemahan Hendra Teguh Edisi ketujuh, penerbit Buana Ilmu Komputer, Jakarta.

Davis, 2003, Pengantar Sistem Informasi Manajemen, Andi Yogyakarta, Yogyakarta

Fahkri, 2005, Pengantar Sistem Informasi Manajemen, Andi Yogyakarta, Yogyakarta

Jogiyanto.HM, 2003, Analisis dan Desain Sistem Informasi, Andi Yogyakarta, Yogyakarta

Kristanto, 2003, Pengantar Sistem Informasi Manajemen, Andi Yogyakarta, Yogyakarta

Leod, Jr, 2002, Analisis dan Desain Sistem Informasi, Andi Yogyakarta, Yogyakarta

LPKBM Madcoms Madiun, 2003, Seri Panduan Pemrograman Microsoft Visual Basic 6.0, Andi Yogyakarta, Yogyakarta

Margono, 2002, Sistem Informasi Manajemen terjemahan Hendra Teguh Edisi ketujuh, penerbit Buana Ilmu Komputer, Jakarta.

Teguh, 2003, Sistem Informasi Manajemen terjemahan Hendra Teguh Edisi ketujuh, penerbit Buana Ilmu Komputer, Jakarta.

Wahyono, 2004, Pengantar Sistem Informasi Manajemen, Andi Yogyakarta, Yogyakarta 